\title{
O FEMINICÍDIO COMO UMA MANIFESTAÇÃO DAS RELAÇÔES DE PODER ENTRE OS GÊNEROS
}

\author{
Maria Fernanda Soares Fonseca* \\ Maria da Luz Alves Ferreira** \\ Rizza Maria de Figueiredo \\ Ágatha Silva Pinheiro ${ }^{* * *}$
}

\begin{abstract}
RESUMO
O presente artigo propõe realizar uma análise sociojurídica da introdução da perspectiva da violência de gênero no ordenamento jurídico brasileiro. Através da apresentação das leis 13.104/2015 e 11.340/2006, com ênfase na primeira que versa sobre o feminicídio, demonstra-se uma especialização da legislação penal que aprimora a punição de homens que matam em razão do gênero. Também foram apresentados a relação da desigualdade de gênero com a ocorrência da violência contra a mulher e sua persistência no decorrer da história da humanidade. Diante dos dados apresentados e da pesquisa realizada, foi possível concluir que a violência de gênero permanece presente na realidade brasileira, vitimando muitas mulheres, fazendo-se necessária a especialização da legislação no sentido de punir, prevenir e erradicar esta forma de violência, que é resultado de uma sociedade eminentemente patriarcalista e machista. Para desenvolvimento deste artigo foi utilizada como metodologia a pesquisa bibliográfica.
\end{abstract}

PALAVRAS-CHAVE: Feminicídio. Violência contra a mulher. Desigualdade de gênero.

\footnotetext{
* Mestranda no Programa de Pós-Graduação em Desenvolvimento Social (PPGDS) da Universidade Estadual de Montes Claros. É professora Orientadora de TCC (Trabalho de Conclusão de Curso) na Funorte.

** Possui doutorado em Ciências Humanas (Sociologia e Política) (2007), pela UFMG. Atualmente é professora do Curso de Ciências Sociais e do Programa de Pós-Graduação em Desenvolvimento Social da Universidade Estadual de Montes Claros.

**** Bacharel em Serviço Social.

Bacharel em Serviço Social.
} 


\begin{abstract}
This article proposes to carry out a social and legal analysis of the introduction of the perspective of gender violence in the Brazilian legal system. Law 13.104/2015 and 11.340/2006, with emphasis on the first one dealing with feminicide, show a specialization of criminal legislation that improves the punishment of men who kill on the basis of gender. The relationship between gender inequality and the occurrence of violence against women and their persistence in the course of human history was also presented. Given the data presented and the research carried out, it was possible to conclude that gender violence remains present in the Brazilian reality, victimizing many women, making it necessary to specialize legislation in order to punish, prevent and eradicate this form of violence, which is the result of an eminently patriarchal and sexist society. For the development of this article was used as methodology the bibliographic research.
\end{abstract}

KEYWORDS: Feminicide. Violence against women. Gender inequality

\title{
INTRODUÇÃO
}

A violência contra a mulher não é um fato recente, desde os primórdios da humanidade as mulheres vêm sendo vítimas de agressões, muitas vezes chegando a óbito. Por outro lado, o que é novo, é a responsabilidade de vencer tal violência, como condição para a construção da humanidade, visto que o Feminícidio define-se como a expressão máxima da violência contra a mulher.

Contemporaneamente, tem-se aumentado a preocupação com o fenômeno da morte de mulheres vítimas da violência de gênero, aperfeiçoando a sua especialização por via da legislação, que consiste na criminalização da violência contra as mulheres, não só pelas normas ou leis, mas, também, através da consolidação de aparelhos mobilizadores que protejam as vítimas e punam seus agressores.

A Lei $n^{\circ} 11.340 / 2006$, conhecida como Lei Maria da Penha, representa um marco na proteção aos direitos das mulheres, pois tem como premissa coibir e prevenir todas as formas de violência doméstica e familiar. Do mesmo modo, em março de 2015, no Brasil, o Feminícidio foi tipificado como conduta criminosa, através da Lei n. 13.104/2015. 
O presente artigo será divido em duas seções, na primeira seção serão apresentados os conceitos de gênero e violência de gênero relacionando a ocorrência desta última como consequência do sistema patriarcalista vigente, e, na segunda seção serão apresentados aspectos sociojurídicos do crime de feminicídio.

\section{METODOLOGIA}

Para se alcançar os objetivos propostos neste artigo, utiliza-se como metodologia a revisão bibliográfica, a fim de trazer os principais conceitos e posicionamentos acerca da temática em questão. Na pesquisa bibliográfica serão utilizados livros, periódicos e artigos científicos, utilizando os seguintes descritores de forma isolada e associada: Violência de gênero e Feminicídio.

O método de análise utilizado será o qualitativo, o qual proporcionará a formulação das discussões sobre os principais resultados e conclusões do estudo.

\section{GÊNERO E VIOLÊNCIA: O SISTEMA PATRIARCALISTA E A VIOLÊNCIA CONTRA A MULHER}

A violência vem sendo motivo de extrema preocupação diante do cenário contemporâneo brasileiro. Deste modo, faz-se necessário apresentar o conceito de violência utilizado neste artigo,

Violência, em seu significado mais frequente, quer dizer uso da força física, psicológica ou intelectual para obrigar outra pessoa a fazer algo que não está com vontade; é constranger, é tolher a liberdade, é incomodar, é impedir a outra pessoa de manifestar seu desejo e sua vontade, sob pena de viver gravemente ameaçada ou até mesmo ser espancada, lesionada ou morta. É um meio de coagir, de submeter outrem ao seu domínio, é uma violação dos direitos essenciais do ser humano. Assim, a violência pode ser compreendia como uma forma de restringir a liberdade de uma pessoa ou de um grupo de pessoas, reprimindo e ofendendo física ou moralmente (TELES, 2003, p. 15).

Observa-se então, que a violência ganha lugar de destaque, uma vez que, encontra-se expressa nas relações cotidianas, 
Diante deste fenômeno, presente no espaço social, encontra-se a violência contra a mulher. O primeiro documento internacional de direitos humanos que aborda esta violência foi aprovado em 1993, na Assembléia Geral das Nações Unidas. Esse documento define violência contra a mulher como qualquer ato de violência baseado no gênero que resulta, ou tenha probabilidade de resultar, dano ou sofrimento físico, sexual e psicológico, incluindo ameaça, coação ou privação arbitrária de liberdade, na vida pública ou privada (SANTI, 2010, p. 418).

Deste modo, importante apresentar o conceito de gênero,

Gênero é um recurso utilizado para se referir à construção social desigual baseada na existência de hierarquia entre os sexos e as consequiências que daí se originam. Essa diferença não é só conceitual, tem efeitos políticos, sociais e culturais (FARAH, 2004, p. 48).

A seu turno, o oposto da igualdade é desigualdade ou inequivalência. No desenvolvimento de seu raciocínio, apresenta-se,

Não é identidade entre homens e mulheres que queremos reclamar, mas uma diversidade historicamente variável mais complexa do que aquela que é permitida pela oposição macho/fêmea, uma diversidade que é também diferentemente expressada para diferentes propósitos em diferentes contextos. Na verdade, a dualidade criada por essa oposição traça uma linha de diferença, investe-a com explanações biológicas, e então trata cada lado da oposição como fenômeno unitário (...). Em contraste, nossa meta é ver não somente diferenças entre os sexos, mas também o modo como essas trabalham para represar as diferenças dentro dos grupos de gênero. A identidade construída em cada lado da oposição binária esconde o múltiplo jogo de diferenças e mantém sua irrelevância e invisibilidade (SCOTT, p. 46, 1986, apud LOURO, p. 116, 1995).

Com relação à violência de gênero, ressalta-se que esta se desenvolve em um contexto em que as relações são produzidas socialmente,

A violência de gênero só se sustenta em um quadro de desigualdades de gênero. Estas integram o conjunto das desigualdades sociais estruturais, que se expressam no marco do processo de produção e reprodução das relações fundamentais - as de classe, étnico-raciais e 
de gênero. A estas relações podem-se agregar as geracionais, visto que não correspondem tão-somente à localização de indivíduos em determinados grupos etários, mas também à localização do sujeito na história, na ambiência cultural de um dado período, na partilha ou na recusa dos seus valores dominantes, nas suas práticas de sociabilidade (ALMEIDA, 2007, p. 28).

A violência contra a mulher, em seu contexto geral, surge de uma diferença biológica entre os sexos, construindo socialmente um sistema de dominação masculina, principalmente no que se refere à divisão social do trabalho, que atribui um papel ideal para cada um dos dois sexos (BOURDIEU, 2010).

Tal violência ocorre em várias esferas da vida e se manifesta sob formas e circunstâncias distintas. Neste contexto, dentre as inúmeras situações de violência que vitimam as mulheres, destacamse, às ocorridas no espaço definido socialmente para as mulheres: o espaço privado, a família e o domicílio (SANTI, 2010).

Conforme Dias (2010), a mulher ficou restrita ao espaço do lar, com a obrigação de cuidar do marido e dos filhos, enquanto ao homem coube o espaço público, o que colaborou para a formação de dois mundos, uma separação que culminou ao homem o espaço da dominação, externo, produtor, já ao outro, coube o espaço da submissão, interno e reprodutor. O provedor da família e a protetora do lar, cada um desempenhando sua função.

Aquino (2015) defende que ao aceitar a esfera privada, as mulheres legitimam a sua sujeição ao sexo oposto, propiciando a dominação masculina, bem como o exercício do poder patriarcal. Afirmando o mencionado, Bourdieu (1999, p. 116) destaca que as mulheres, uma vez excluídas da esfera pública, ou seja do "universo das coisas sérias", elas "ficaram durante muito tempo confinadas ao universo doméstico e às atividades associadas à reprodução biológica e social da descendência", adiciona-se a isso o fato de que o trabalho doméstico das mulheres, ainda nos dias atuais, não faz jus a remuneração alguma, contribui para desvalorizá-la e perpetuar a dominação patriarcal.

Os diferentes padrões de comportamento estabelecidos para homens e mulheres geram a construção de um código de conduta. Ao macho é atribuído um papel paternalista, colocando a fêmea em uma 
situação de submissão. Partindo disso, há uma diferença na educação das mulheres, moldadas para serem controladas e terem seus desejos reprimidos. Por isso, a restrição ao exercício da sexualidade e a consagração da maternidade. Ambos os universos, distantes, mas dependentes entre si, buscam manter suas contradições estabelecidas, mantendo o modelo de submissão alicerçado no autoritarismo (DIAS, 2010).

Enfatizando, que a violência de gênero se passa num quadro de disputa pelo poder, o que significa que não é dirigida a seres, em princípio, submissos, mas revela que o uso da força é necessário para manter a dominação, porquanto a ideologia patriarcal - tensionada por conquistas históricas, sobretudo feministas - não se revela suficientemente disciplinadora (ALMEIDA, 2007, p. 28).

É importante salientar, que a dominação é masculina, e a consequente violência contra a mulher tem sua origem no patriarcado, uma vez que este sistema permite a superioridade masculina nas relações de gênero. Por sua vez, conforme acima apresentado a violência de gênero produz e se reproduz nas relações de poder em que se enlaçam homens e mulheres (ARAÚJO, 2004).

Assim, no que se refere à função patriarcal, cabe aos homens designar e estabelecer normas e punições ao que lhes apresentar como desvio, ainda que, não haja por parte das vítimas a tentativa de trilhar caminhos distintos aos regidos pelas normas sociais (SAFFIOTI, 2001).

Deste modo, faz-se necessário apresentar o conceito de Patriarcalismo,

O patriarcalismo é uma das estruturas sobre as quais se assentam todas as sociedades contemporâneas. Caracteriza-se pela autoridade, imposta institucionalmente, do homem sobre a mulher e filhos no âmbito familiar. Para que essa autoridade possa ser exercida, é necessário que o patriarcalismo permeie toda a organização da sociedade, da produção e do consumo à política, à legislação e à cultura. Os relacionamentos interpessoais e, consequentemente, a personalidade, também são marcados pela dominação e violência que têm sua origem na cultura e instituições do patriarcalismo (CASTELLS, 2010, p. 169). 
De tal modo, Campos (2012) descreve alguns fatores que contribuem para a prática da violência contra a mulher, sendo estes: a falta de punição dos agressores, o silêncio das mulheres agredidas, a inferioridade das mulheres e a transformação das vítimas em culpadas. Portanto, a violência contra a mulher representa um verdadeiro desrespeito aos direitos e garantias fundamentais da mulher, colocando-se como um obstáculo para a efetivação de uma série de princípios constitucionais, tais como a dignidade da pessoa humana, da igualdade, da liberdade, dentre outros.

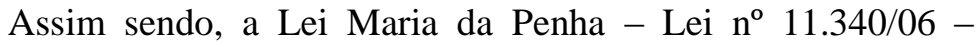
representa um marco na proteção aos direitos das mulheres, pois, de maneira geral teve como premissa essencial coibir e prevenir todas as formas de violência doméstica e familiar, nos termos do artigo 226 da Constituição Federal de 1988, da Convenção sobre a Eliminação de Todas as Formas de Discriminação Contra as Mulheres e da Convenção Interamericana para Prevenir, Punir e Erradicar a Violência Contra a Mulher, ratificado pelo Brasil.

No período anterior à Lei, de 1980 até 2006, o crescimento do número de homicídios de mulheres foi de 7,6\% ao ano. Já no período de 2006 até 2013, após a vigência da Lei, decresce o número desses homicídios para $2,6 \%$ ao ano e das taxas para $1,7 \%$ ao ano (WAISELFISZ, 2015).

Ainda considerando Waiselfisz (2015), no período assimilado entre 2003 e 2013, o número de mulheres vitimadas pela violência no Brasil passou de 3.937 para 4.762, impulsionando um aumento de 21,0\% na década. Essas 4.762 mortes em 2013 representam cerca de 13 homicídios femininos diários. Partindo do pressuposto de que o crescimento da população feminina nesse período passou de 89,8 para 99,8 milhões (crescimento de $11,1 \%$ ), observa-se que a taxa nacional de homicídio, que em 2003 era de 4,4 por 100 mil mulheres, passa para 4,8 em 2013, crescimento de 8,8\% na década.

Limitando a análise ao período regido pela Lei Maria da Penha, com início de vigência em 2006, a maior parte desse aumento decenal das mortes aconteceu sob o período de respaldo da nova lei: $18,4 \%$ nos números e $12,5 \%$ nas taxas, entre 2006 e 2013. Dado um primeiro momento, em 2007, registrou-se uma queda expressiva nas taxas, de 4,2 para 3,9 por 100 mil mulheres, mas rapidamente alavancaram-se os índices de homicídios, ultrapassando a taxa de 
2006. Não obstante ao contexto apresentado, observa-se uma queda nesse quadro a partir de 2010 (WAISELFISZ, 2015).

As mortes de mulheres por questões de gênero, chamadas de feminicídio, encontram-se presentes em todos os níveis da sociedade e, conforme anteriormente apresentado, são decorrentes de uma cultura de dominação e desigualdade nas relações de poder existente entre homens e mulheres, produzindo a inferiorização da condição feminina, resultando na forma mais extrema da violência contra as mulheres, que é o óbito (OLIVEIRA, 2015).

Confirmando esse ponto de vista, Romero (2014) vem endossar que o feminicídio é todo e qualquer ato de violência proveniente da dominação de gênero e que é praticado contra a mulher, ocasionando sua morte. Partindo dessa concepção, o assassinato de mulheres pode ser realizado por pessoas próximas das vítimas, como namorados, maridos e/ou companheiros, outros membros da família ou por desconhecidos.

São crimes cujo impacto é silenciado, praticados sem distinção de lugar, de cultura, de raça ou de classe, além de ser a expressão perversa de um tipo de dominação masculina ainda fortemente cravada na cultura brasileira. Cometidos por homens contra as mulheres, suas motivações são o ódio, o desprezo ou o sentimento de perda da propriedade sobre elas (AQUINO, 2015, p. 11).

Diante deste contexto real de violência e discriminação é que ressalta-se a importância de leis como a Lei 13.104/2015 que será apresentada de forma mais detalhada em seus aspectos sociojurídicos na próxima seção.

\section{ASPECTOS SOCIOJURÍDICOS DO FEMINICÍDIO}

O reconhecimento do feminicídio como crime hediondo enquanto alternativa para coibir a violência de gênero objetiva assegurar às mulheres os seus direitos e garantias fundamentais, uma vez que sua tipificação, por intermédio da Lei $n^{\circ} 13.104 / 2015$, expressa o início de uma mudança jurídica e social na consciência coletiva e um instrumento protetivo da violência contra as mulheres.

Inicialmente insta salientar que um dos marcos mais importantes 
e relevantes no que concerne à luta pela proteção das mulheres em face da violência doméstica foi a Lei Maria da Penha, que é o resultado da atuação dos movimentos feministas e da tramitação do caso Maria da Penha versus Brasil na Comissão Interamericana de Direitos Humanos, no ano de 2001. A partir de então, o Estado brasileiro iniciou o processo de revisão das estratégias e políticas públicas de defesa dos direitos humanos das mulheres, e, dentre algumas das providências, ressalta-se a criação da referida lei como um dos mais significativos e relevantes avanços legislativos relacionados ao combate à violência contra a mulher, por denunciar o cotidiano de violência doméstica e tornar visível uma violação de direitos protegida pela esfera da vida privada (MACHADO et al., 2015).

As providências do Estado brasileiro para a promoção e proteção das mulheres são contemporâneas das de outros países na América Latina, onde, atualmente, 14 países possuem legislação que reconhecem o feminicídio como crime, além do Brasil (MACHADO et al., 2015).

Apesar de representar um marco na luta pelos direitos das mulheres, de todas as inovações e conquistas, uma década depois da publicação da Lei Maria da Penha, alguns questionamentos são apontados, no que se refere a sua efetividade com relação ao enfrentamento à violência contra a mulher.

Neste sentido, Campos (2012) pontua que, no que concerne ao reconhecimento de direitos, não restam dúvidas que a supracitada lei foi efetiva,

Em análise à Lei 11.340/06, observamos que a mesma detém consideráveis repercussões no âmbito jurídico, criando trâmite inovador de garantia, decorrentes dos acréscimos efetivados no campo do Direito Penal, do Processo Penal, da Execução Penal, do Direito Civil, do Processo Civil, do Direito Administrativo, do Direito Trabalhista e do Previdenciário, tudo isso para maximizar a ordem jurídica no que se refere à integração sistêmica de benefícios assistenciais e de proteção, buscando, sempre a devida concreção dos direitos e garantias fundamentais, na máxima constitucional do princípio da inafastabilidade (CAMPOS, 2012, p. 145).

No entanto, verifica-se que a mesma não está sendo de fato efetiva para coibir a prática mais extrema de violência, que é o 
assassinato de mulheres em decorrência do gênero, fazendo-se necessário o reconhecimento do feminicídio como novo tipo penal previsto no Código Penal brasileiro.

Em virtude dessa realidade, em março de 2015, no Brasil, o feminicídio foi tipificado como conduta criminosa através da Lei $\mathrm{n}^{\circ}$ 13.104/2015, na qual o Estado reconhece quão grave e danoso é, para a sociedade, o homicídio de mulheres, no sentido de promover a justiça de gênero com o propósito de diminuir as práticas discriminatórias ainda presentes no Direito e no Poder Judiciário. Entretanto, o debate referente ao feminicídio ainda suscita controvérsias e tensões, pela compreensão de que a simples judicialização, ou seja, a tipificação da conduta violenta como crime não seria o caminho mais eficaz para a mitigação ou o banimento deste fenômeno da realidade social (GOMES, 2015).

A Lei de Feminicídio foi criada a partir de uma recomendação da Comissão Parlamentar Mista de Inquérito sobre Violência contra a Mulher (CPMI-VCM) que investigou a violência contra as mulheres nos Estados brasileiros, de março de 2012 a julho de 2013, a Comissão teve "a finalidade de investigar a situação da violência contra a mulher no Brasil e apurar denúncias de omissão por parte do poder público com relação à aplicação de instrumentos instituídos em lei para proteger as mulheres em situação de violência" (BRASIL, 2013).

Contudo, há de se considerar que a iniciativa do poder legislativo é o resultado do empoderamento político das mulheres, que passam a se reconhecer como sujeitos sociais detentores de direitos e, consequentemente, começam a cobrar tal reconhecimento da própria sociedade que, por sua vez, não poderia ficar estagnada em virtude dessa realidade.

A lei 13.104/15, que introduziu o feminicídio como uma das qualificadoras do crime de homicídio, alterou o Código Penal brasileiro, punindo de forma mais rigorosa os agressores que cometerem o homicídio em função da condição do sexo, alterando também o art. 121 do Decreto-Lei no 2.848/1940 (Código Penal), para prever o feminicídio como circunstância qualificadora do crime de homicídio, e o art. $1^{\circ}$ da Lei $n^{\circ} 8.072 / 1990$, para incluir o feminicídio no rol dos crimes hediondos. Desta forma, há mais uma modalidade de homicídio qualificado: o feminicídio, quando crime 
for praticado contra a mulher por razões da condição de sexo feminino.

A novel lei dispõe que:

Homicídio qualificado $\S 2^{\circ}[\ldots]$

Feminicídio

VI - contra a mulher por razões da condição de sexo feminino:

$\S 2^{\circ}$ - A Considera-se que há razões de condição de sexo feminino quando o crime envolve:

I - violência doméstica e familiar;

II - menosprezo ou discriminação à condição de mulher.

Aumento de pena

$\S 7^{\circ}$ A pena do feminicídio é aumentada de $1 / 3$ (um terço) até a metade se o crime for praticado:

I - durante a gestação ou nos 3 (três) meses posteriores ao parto;

II - contra pessoa menor de 14 (catorze) anos, maior de 60 (sessenta) anos ou com deficiência;

III - na presença de descendente ou de ascendente da vítima.

A referida lei não se limita apenas a uma modificação da esfera legislativa no Brasil, cujo caráter esteja restrito ao seio simbólico das normas jurídicas, mas ensejando avanços inclusive no comportamento e na relação com o gênero feminino, de modo a não só garantir direitos e sim, essencialmente, assegurar sua efetiva proteção (SIMIONATO, 2015).

A supracitada lei que tipifica o feminicídio como homicídio qualificado, o considera crime hediondo, onde a pena prevista para o homicídio qualificado é de 12 a 30 anos de reclusão. Os crimes hediondos, por sua vez, são considerados de extrema gravidade e, por isso, recebem um tratamento mais severo por parte do legislador. Isto quer dizer que os casos de violência doméstica e familiar ou menosprezo e discriminação contra a condição feminina, passam a ser vistos como qualificadores (condição que agrava a conduta delituosa e, consequentemente, a pena imputada a quem o pratica) do crime, se, por ventura, essa violência resultar em homicídio (OLIVEIRA, 2015).

Com relação ao conceito de feminicídio, Pasinato (2011) aduz que, para se caracterizá-lo, o ato (matar) não pode ser isolado, deve existir histórico de violência e de intencionalidade. 
[...] outra característica que define femicídio é não ser um fato isolado na vida das mulheres vitimizadas, mas apresentar-se como o ponto final em um continuum de terror, que inclui abusos verbais e físicos e uma extensa gama de manifestações de violência e privações a que as mulheres são submetidas ao longo de suas vidas. Sempre que esses abusos resultam na morte da mulher, eles devem ser reconhecidos como femicídio (PASINATO, 2011, p. 224).

Por outro lado, para que o crime seja qualificado como Feminicídio, conforme previsto na lei de 2015 é essencial que o mesmo apresente duas características: a violência doméstica e familiar (art. 121, § $2^{\circ}$-A, I), e o menosprezo ou discriminação da condição de mulher (art. 121, § $2^{\circ}$-A, II). Outra perspectiva para a caracterização dessa conduta delituosa é o menosprezo da condição feminina (art. 121, § $2^{\circ}$-A, II do Código Penal Brasileiro), em virtude da relação de poder e submissão do agente sobre a vítima, que acaba sendo oprimida e humilhada em decorrência de seu gênero (OLIVEIRA, 2015).

A presença dos filhos no cenário violento e o fato destes presenciarem, muitas vezes, os maus-tratos destinados a mãe, impôs ao legislador a determinação de aumentar o tempo da sanção ao agressor, se o homicídio for executado na presença de descendente ou de ascendente da vítima (art. 121, $\S 7^{\circ}$, III do Código Penal), ou se for concretizado durante a gestação ou até três meses após o parto (art. $\left.121, \S 7^{\circ}, \mathrm{I}\right)$, pois o legislador entendeu que a gestação é um período de intensa fragilidade feminina, e que além da obrigação do Estado de preservar a vida e a saúde da gestante, possui igual dever de preservar a vida e a saúde do nascituro que está em desenvolvimento (OLIVEIRA, 2015).

Ainda de acordo com supracitado autor, em face das condições de agravamento da pena para o feminicídio, a lei impõe que este acréscimo sobrevenha em casos nos quais o homicídio se dê em desfavor de crianças menores de quatorze anos, em idosas com mais de sessenta anos e em portadoras de deficiência conforme pontua $\mathrm{o}$ (art. 121, § $\left.7^{\circ}, \mathrm{I}\right)$.

Ressalta-se que a importância da tipificação do delito, também ofereceu maior riqueza de possibilidades regulatórias, tendo em vista que, em geral, não só adotaram normas de comportamento 
acompanhadas de sanções para reprimir o feminicídio, mas também normas jurídicas de conteúdo não punitivo que promoveram mudanças processuais, criação de instituições e de políticas públicas voltadas à proteção da mulher (PIRES, 2016).

Neste cenário, a tipificação penal do feminicídio foi apontada por especialistas como uma importante e necessária ferramenta para denunciar a violência sistêmica contra mulheres em relações conjugais, que muitas vezes resulta em homicídios encarados como crimes passionais pela sociedade, pela mídia e até mesmo pelo sistema de judiciário (PRADO, 2017).

Tendo em vista que o feminicídio é o assassinato de uma mulher pela condição de ser mulher, nota-se que são crimes que ocorrem geralmente na intimidade dos relacionamentos e com frequência caracterizam-se por formas extremas de violência e barbárie. São crimes cujo impacto é silenciado, praticados sem distinção de cultura, de raça, de lugar ou classe social, além de ser a expressão perversa de um tipo de dominação masculina ainda fortemente cravada na cultura brasileira. Cometidos por homens contra as mulheres, onde suas motivações são o ódio, o desprezo ou o sentimento de perda da propriedade sobre elas (AQUINO, 2015).

Como bem definiu o Relatório Final da Comissão Parlamentar Mista de Inquérito sobre a Violência contra a Mulher (CPMI) do Congresso Nacional:

O feminicídio é a instância última de controle da mulher pelo homem: o controle da vida e da morte. Ele se expressa como afirmação irrestrita de posse, igualando a mulher a um objeto, quando cometido por parceiro ou ex-parceiro; como subjugação da intimidade e da sexualidade da mulher, por meio da violência sexual associada ao assassinato; como destruição da identidade da mulher, pela mutilação ou desfiguração de seu corpo; como aviltamento da dignidade da mulher, submetendo-a a tortura ou a tratamento cruel ou degradante (BRASIL, 2013, p. 1003).

Conforme Machado (2011), o feminicídio é uma categoria ainda em construção no Brasil, tanto no campo sociológico quanto no campo jurídico, uma vez que a violência está enraizada nas estruturas sociais, assim como é parte da 'aprendizagem' no sistema de socialização, independentemente dos padrões socioeconômicos de 
pertencimento. Diante desse contexto, a tipificação do crime de feminicídio visa contribuir para a construção de políticas de enfrentamento a essa forma extrema de violência.

Para além do agravo da pena, o aspecto mais relevante da tipificação, segundo especialistas, é chamar atenção para o fenômeno e promover uma compreensão mais acurada sobre sua dimensão e características nas diferentes realidades vividas pelas mulheres no Brasil, permitindo assim o aprimoramento das políticas públicas para coibi-lo (PRADO, 2017).

Para Castells (2010), a atuação efetiva e eficaz do Estado para prevenir os assassinatos praticados contra as mulheres inclui a devida atenção aos casos de agressões consideradas menos graves, o cumprimento da punição dos agressores e a garantia aos direitos humanos das mulheres.

Conforme exposto, muitas foram às mudanças nos discursos legislativos e jurídicos com relação aos direitos das mulheres. Criminalizar o feminicídio foi uma providência necessária e justa, diante da dívida que a sociedade possui para com as mulheres, todavia, a judicialização do feminicídio é apenas uma das muitas modificações que o Estado deve empreender a fim de transformar definitivamente essa realidade (OLIVEIRA, 2015).

\section{CONCLUSÃO}

Tal como apresentado neste artigo, a violência imposta às mulheres é observada no decorrer da história da humanidade e tem sua gênese em um modelo construído socialmente que promove a dominação, determinando os papéis de cada gênero em sociedade, a partir de representações e comportamentos que devem ser obedecidos, alicerçado em um sistema que legitima a sujeição do outro. Por conseguinte, este modelo social implica na violação de direitos, submetendo as mulheres à uma condição de inferioridade em relação aos homens, exemplificada através de vários tipos de violência, chegando até a consumação da morte, o feminicídio.

Desse modo, na tentativa de minimizar a violência contra as mulheres, a Lei do Feminicídio entrou em vigência em março de 2015, como uma qualificadora penal e que reconhece o homicídio de mulheres como crime hediondo, este resultando de violência 
doméstica e familiar ou em razão de menosprezo ou discriminação da condição de mulher.

Em face da luta por justiça de gênero, a criminalização do feminicídio, para além de um caráter simbólico das normas jurídicas, é importante como um dos meios para garantir a efetivação da igualdade entre as pessoas e da dignidade humana. Assim, a especialização da legislação implica na luta pela erradicação da violência e na inserção do feminicídio como uma política de Estado, pois a morte de mulheres, decorrente da discriminação e violência de gênero, ultraja a consolidação dos direitos humanos.

\section{REFERÊNCIAS}

ALMEIDA, Suely Souza de. (org.) Violência de gênero e políticas públicas. Rio de Janeiro, Editora UFRJ, 2007.

AQUINO, Quelen Brondani de; KONTZE, Karine Brondani. O feminicidio como tentantiva de coibir a violência de gênero. Anais da semana acadêmica: Fadisma Entrementes. ed. 12. 2015.

ARAÚJO, Maria de Fátima; MATTIOLI, Olga Ceciliato. Gênero e violência. Arte \& Ciência, 2004.

BOURDIEU, Pierre. A dominação masculina. Bertrand Brasil, 2010.

BOURDIEU, Pierre. A Dominação Masculina. Tradução de Maria Helena Kühner. Rio de Janeiro: Bertrand Brasil, 1999.

BRASIL, Senado Federal. Comissão Parlamentar Mista de Inquérito. Relatório Final. Brasília, julho de 2013. Disponível em: <https://www12.senado.leg.br/institucional/omv/entendaaviolencia/pdfs/relatorio-final-da-comissao-parlamentar-mista-de-inqueritosobre-a-violencia-contra-as-mulheres > . Acesso: 09 de Abr. 2017.

. Presidência da República. Lei $n^{0}$ 11.340, de 7 de agosto de 2006.Disponível em: http://www.planalto.gov.br/ccivil 03/_ato20042006/2006/lei/111340.htm>. Acesso em: 12 de abr. 2017.

. Presidência da República. Lei no 13.104, de 9 de março de 2015. Disponível em: http://www.planalto.gov.br/ccivil_03/_ato20152018/2015/Lei/L13104.htm>. Acesso em: 12 de abr. 2017.

CAMPOS, Amini Haddad; CORRÊA, Lindinalva Rodrigues. Direitos Humanos das Mulheres. Curitiba: Juruá, 2012. 
CASTELLS, Manuel. O poder da identidade. São Paulo: Paz e Terra, 2010.

DIAS, Maria Berenice. Manual de Direito das Famílias. $7^{\text {a }}$ ed. São Paulo: Ed. RT, 2010.

FARAH, Marta Ferreira Santos. Gênero e Políticas Públicas. Estudos Feministas, Florianópolis, 12 (1): 47-71, janeiro-abril/2004.

GOMES, Izabel Solyszko. Feminicídios e possíveis respostas penais: dialogando com o feminismo e o direito penal. Revista Gênero \& Direito, v. 4, n. 1, 2015.

LOURO, Guacira Lopes. Gênero, história e educação: construção e desconstrução. Educação \& realidade, v. 20, n. 2, 1995.

MACHADO, Lia Zanatta. Feminismo brasileiro: revolução de ideias e políticas públicas. In: SOUSA JUNIOR, José Geraldo; APOSTOLOVA, Bistra Stefanova; FONSECA, Lívia Gimenes Dias da. (orgs.) O Direito Achado na Rua, vol. 5. Introdução crítica aos direito das mulheres. Brasília: CEAD, FUB, 2011.

MACHADO, Marta Rodrigues de Assis. (org.). A violência doméstica fatal: o problema do feminicídio íntimo no Brasil. Diálogos sobre Justiça. Brasília, DF: Ministério da Justiça, 2015. Disponível em: 〈http://www.pnud.org.br/arquivos/publicacao_feminicidio.pdf $>$. Acesso: 09 abr. 2017.

OLIVEIRA, Ana Carolina Gondim; COSTA, Mônica Josy Sousa; SOUSA, Eduardo Sérgio Soares. Feminicídio e violência de gênero: aspectos sociojurídicos. Revista Tema, v. 16, n. 24/25, janeiro a dezembro de 2015.

PASINATO, Wânia.Femicídiose as mortes de mulheres no Brasil. Cadernos Pagu, n. 37, p. 224, 2011. Disponível em: 〈http://www.scielo.br/pdf/cpa/n37/a08n37.pdf >. Acesso: 09 abr. 2017.

PIRES, Julie Ferreira. O direito das mulheres no cenário sociojurídico brasileiro e o feminicídio: Quando a violência doméstica se torna fatal. 2016.

PRADO, Débora; SANEMATSU, Marisa (orgs.).Feminicídio invisibilidade mata. Fundação Rosa Luxemburg. São Paulo: Instituto Patrícia Galvão, 2017.

ROMERO, Tereza Incháustegui. Sociologia e política de feminicídio: algumas chaves interpretativas a partir do caso mexicano. Revista Sociedade e Estado, Brasília, v. 29, n. 2, p. 373-400, maio/ago.2014. Disponível em: 〈http://www.scielo.br/pdf/se/v29n2/04.pdf>. Acesso: 20 abr. 2017. 
SAFFIOTI, Heleieth IB. Contribuições feministas para o estudo da violência de gênero. Cadernos pagu, n. 16, p. 115-136, 2001.

SANTI, Liliane Nascimento de; NAKANO, Ana Maria Spanó; LETTIERE, Angelina. Percepção de mulheres em situação de violência sobre o suporte e apoio recebido em seu contexto social. Texto \& Contexto Enfermagem, v. 19, n. 3, p. 417-424, 2010.

SCOTT, Joan. Gender and the Politics of History. Nova Iorque: Columbia University Press, 1986.

SIMIONATO, Girlene Nascimento; MICHILES, Ronaldo. Feminicídio: Uma realidade brasileira. Revista de Produção Acadêmico-Científica, Manaus, v. 2, n. ${ }^{\circ} 1,2015$.

TELES, Maria Amélia de Almeida; MELO, Mônica de. O que é violência contra a mulher. São Paulo: Brasiliense, 2003.

WAISELFISZ, Julio Jacobo. Mapa da violência 2015. Atualização: homicídios de mulheres no Brasil, 2015. 
